\title{
Extreme Climatic Variability in North-western Nigeria: An Analysis of Rainfall Trends and Patterns
}

\author{
Imo J Ekpoh (Corresponding author) \\ Department of Geography, University of Calabar, Calabar, Nigeria \\ E-mail: imyjay55@yahoo.com \\ Ekpenyong Nsa (FRGS) \\ Climate Change Research Unit, Global Tree Planters, Abuja, Nigeria \\ E-mail: nsa.ekpenyong@yahoo.com
}

Received: November 4, 2010 Accepted: November 30, 2010 doi:10.5539/jgg.v3n1p51

\begin{abstract}
Some aspects of the climate of north-western Nigeria were examined in this study, focusing more on rainfall, its inter- and intra-annual variability and patterns of distribution. Adopting the statistical distributions commonly used to describe climate states such as the mean, the standard deviation and the coefficient of variability, the climate of north-western Nigeria was analyzed for possible shifts in mean conditions and patterns. The study found that climatic conditions in north-western Nigeria have altered substantially as four drought episodes took place within the last three decades of the $20^{\text {th }}$ Century and, the 1984 drought-year rainfall was 58.8 percent lower than the long-term mean rainfall. The study further showed that the 1968 to 2008 mean rainfall shifted downwards by 8.8 percent from the long-term mean, although it cannot be said if the shift is permanent or temporary since recent rainfall trends tend to suggest a recovery. Possible options for stabilizing the regional climate are suggested.
\end{abstract}

Keywords: Climate change, Drought, Rainfall analysis, North-western Nigeria

\section{Introduction}

Climatic variation in northern Nigeria is not altogether new because this part of Nigeria contains a significant portion of the Sudan-Sahel ecological zone of West Africa. However, since the early 1970s, climatic anomalies in the form of recurrent droughts, frightening dust storms and rampaging floods have overprinted their rhythms, creating short-duration climatic oscillations as against the normal cycles of larger amplitudes. Thus the last 40 years have witnessed four severe droughts, numerous dust storms and three killer floods. Indeed, the climate of the region has become highly unpredictable, making many people to wonder what has happened to the climate.

The persistence of drought in parts of northern Nigeria during the 1970s, 1980s and 1990s has been attributed to the prevalence of a stagnated anti-cyclonic circulation of the tropical atmosphere over areas that normally should be exposed to the rising arm of the tropical Hadley Cell circulation by mid-summer (Kalu, 1987; Adefolalu, 1986; Kamara, 1986). These conditions are themselves related to the tropical component of the global general circulation system. Tropical circulation patterns are particularly influenced by heat inputs from such sources as warm ocean surfaces acting through latent heat released in deep cumulus convection (Lockwood, 1988). Related heat sources which also have important bearing on tropical circulations are high plateaus and equatorial rainforests (Nicholson and Tucker, 1998). These heat sources display visible latitudinal and longitudinal variations, and also a marked tendency to vary on both annual and, in case of oceans, non-annual scales. One of the consequences of these circulation patterns is that rainfall patterns in West Africa, including northern Nigeria, show both annual and greater than annual variations and also marked tele-connections with distant locations (Nicholson, 1985; 1993).

Most of the droughts that occur in this region have been found to be associated with a late start of the rainy season and early cessation of the rains, resulting in drastic reductions of the length of the rainy season. For instance, a number of studies within the Sahel region have shown a significant trend towards false onset (false onset is a situation where the rainy season starts normally and then ceases abruptly, creating a dry period 
between the false onset and the true onset; see Figures. 6 and 8), late or delayed onset (late or delayed onset is a situation where the expected start of the rainy season is delayed; see Figure. 7) and early cessation (early cessation is a situation where the rainy season stops far ahead of the expected time, Figures. 6 and 7) of the summer rains over a 30-year period from 1969 to 1998 ( Houndenou and Hernandez, 1998; Ekpoh, 1999a; Camberlin and Diop, 2003). In addition, long- term rainfall analysis for the area has observed frequent appearances of false onsets, as well as, a trend towards a pronounced decrease in annual rainfall amounts (Ekpoh, 1999a, Floyd and Ekpoh, 2007).

While rainfall variability is a major characteristic of the Sahelian climate, the last 40 years since 1969 have witnessed dramatic reductions in mean annual rainfall throughout the region (Diop, 1996; Le Barbe and Lebel, 1997; Ekpoh, 1999a; Hulme, 2001; Camberlin and Diop, 2003; Giannini et al., 2003; Dai et al., 2004). According to the Intergovernmental Panel on Climate Change, a rainfall decrease of 29 - 49 percent has been observed in the 1968 - 1997 period compared to the 1931 - 1960 baseline period within the Sahel region (IPCC, 2001). Also, a study conducted in Senegal showed a significant trend towards earlier cessation dates of the summer rains over a 43 year period from 1950 to 1992, with abrupt shift occurring around 1970 (Camberlin and Diop, 2003). Other studies conducted in this region have also noticed a trend towards delayed onset and early cessation, resulting in a shorter rainy season (Houndenon and Hernandez, 1998; Traore et al., 2000).

With further significant variations in the climate of the Sahel being predicted by General Circulation Models (GCMs), it is important that scientific studies be undertaken at regional levels so as to provide society with accurate information on the real and potential impacts of extreme climatic variability, as well as, the mitigation and adaptation options available. At a time when the world is grappling with diverse environmental problems including global warming, ozone depletion, acid rain, killer hurricanes, destructive thunderstorms, recurrent droughts and major flood episodes, any effort at finding explanations to these and other problems should be quite significant, since the environmental, social and economic cost of extreme climatic variability is bound to be enormous from the standpoint of society and human activity.

\section{Causes of drought in the West African Sahel}

Drought is a condition of extreme but short term climatic variation which results in insufficient rainfall to meet the socio-economic demands of a region in terms of water supply for domestic and industrial uses, agriculture and ecosystem. One of the earliest and most influential explanations of the cause of drought in the Sahel was that of Charney et al. (1977), which suggested that reductions in rainfall were the result of human activity. In what has come to be known as Charney's model, decreases in vegetation cover caused by over-grazing and deforestation lead to an increase in the reflectivity or albedo of the land surface. The essence of Charney's hypothesis is that this increase in reflectivity results in a reduction in the heating of the ground, which in turn reduces the heating of the atmosphere by the ground, resulting in a reduction in the convection that is essential for the formation of rainfall-generating clouds. The notion that the people of the Sahel have systematically degraded their lands through forest clearing, overgrazing, and inappropriate land-use practices has been an article of faith to many observers and researchers since the 1920 s, especially by visitors to the region who have very often misinterpreted variations in annual rainfall amounts and decreases in vegetation cover, as evidence of environmental change or the encroachment of the Sahara desert. Also, drought in the region used to be attributed to a simple southward displacement of the Inter-Tropical Convergence Zone (ITCZ). This rather simplistic explanation has been rejected because it failed to explain many important characteristics of rainfall such as late onset or early cessation (Nicholson, 1989, 1993). Other studies have even suggested that the build-up in atmospheric dust, exacerbated by anthropogenic factors such as fire-wood exploitation, bush burning and poor farming practices, as well as, frequent sand storms, which cause changes in surface albedo may be responsible for large-scale climatic alterations in the Sahel (Ekpoh, 2007).

However, modulation of the African Monsoon by regional and global- scale patterns of sea- surface temperature (SST) provides the best explanation for variations in Sahelian rainfall on multi- year to decadal time-scales. Relationships between SST patterns and Sahelian rainfall are well established from statistically based climatological analyses and have been used with some success in seasonal rainfall forecasts in the region (Folland et al., 1986; Ward et al, 1993). Since the late 1960s, the Sahelian drought has been shown to have tele-connections with El Nino Southern Oscillation (ENSO), a phenomenon that is associated with periodic fluctuation in the intensity of the inter-tropical atmospheric and oceanic circulations that is usually coincident with an anomalous warming of the Eastern Tropical Pacific Ocean (Nicholson, 1989, 1993; Foland, Palmer and Parker, 1986; Ekpoh, 1991; Akonga, 2001). Recent work by Giannini et al, (2003) further identified SST as the principal driver of Sahelian rainfall variability, which they modeled successfully for the period 1930-2000, using a model that also represent the land-atmosphere interaction, via moisture feedbacks. Other studies that similarly 
used long-term data from a number of synoptic stations in Nigeria also yielded some very useful information on the recurrence, persistence and periodicity of severe droughts in Nigeria (Adefolalu, 1985, 1986; Tarhule and Woo, 1998).

Available evidence on the nature of rainfall variability in northern Nigeria suggests that a single overall mean periodicity is not observed. Rather, rainfall is primarily characterized by a multiple, non-symmetric cycle of anomalies with varying magnitudes. These observations confirm earlier findings by Bunting et al. (1976). The cycles vary from 3 to 5 years in some locations, and from 10, 20, and 30 to 40 years in others (Kalu, 1987). However, Winstanley (2003) has pointed out that the climatic zones in the northern hemisphere slowly shifted northward for about a century until around 1930. Since then, there has been southward movement, and therefore reduced rainfall in the Sudano-Sahelian region of West Africa. The contention is that the southward movement is likely to continue until about 2030, as part of a 200 -year cycle. A long run of dry years since the early 1970s has also been confirmed for the region (Olaniran and Sumner, 1988; Olaniran, 1991; Easterling and Peterson, 1995). Rainfall analysis performed by Adefolalu (2007) also indicated that both the amount and area of the secondary rainfall maximum at $9^{0} 10^{1} \mathrm{~N}$ latitude in Nigeria has declined with time. At the same time, the belt of relative minimum rainfall appears to be expanding temporally. These aberrations, which imply a decrease in the dry season contribution to annual rainfall, suggest a drier environment in the long-term. Tarhule and Woo (1998) have also used climatic records from 25 locations in northern Nigeria to examine recent changes in several rainfall characteristics of northern Nigeria. The study used the Pettitt and the Mann-Kendall tests to analyze abrupt changes and trends in the rainfall data. The results confirm abrupt changes in the time series of annual rainfall and a significant reduction in the number of rain days, especially for locations north of latitude $11^{0} \mathrm{~N}$. In another study, Ekpoh (2007) conducted station analysis using long-term rainfall data from Katsina, Zaria and Kano to test for trend using the 5-year running means. Results from the study indicated a decrease in annual rainfall in the three stations from 1969 up to 1999.

Today, there is sufficient evidence of rising global temperatures due to increased emission of greenhouse gases (Carbon dioxide, Nitrous oxide, Methane and Chlorofluorocarbons) into the atmosphere. The increased global warming has the capacity to trigger large-scale climatic disturbances, which ultimately may have significant impact on the Sahel rainfall (Biasutti and Giannini, 2006). In spite of this, no satisfactory explanation has yet been offered for the causes of the West African sahelian drought, although scientists agree that the causes are primarily related to large-scale patterns of atmospheric circulation. The emphasis on large-scale patterns rather than local or regional patterns thus support the well-known hypothesis that Sahelian drought is anthropogenically produced as a result of poor land management practices (Nicholson, 1989; Ekpoh, 2003; 2007). Nonetheless, climate experts are quick to point out that, while the Sahel drought which began in 1968 may be unusual because of its length, an examination of historical information (such as variations in the levels of the Lake Chad) suggest that it may be just another episode in the region's long-term climatic history. This caution is anchored on the fact that the issue of climate change is perhaps the most controversial in the entire science of meteorology, in the sense that there are no strict criteria on how many dry years should occur in the Sahel to justify the use of the term "climate change" (Newell and Kidson, 1984; Quinlan, 1985; Todorov, 1986; Folland et al., 1986; Gonzalez, 2001; Giannini, Saravanan and Change, 2003).

\section{The study area}

The study area is north-western Nigeria, encompassing the three states of Sokoto, Kebbi and Zamfara (Fig. 1). The area is found between latitudes $10^{\circ} \mathrm{N}$ and $13^{\circ} 58^{\prime} \mathrm{N}$; and longitudes $4^{\circ} 8^{\prime} \mathrm{E}$ and $6^{\circ} 54^{\prime} \mathrm{E}$. The area so defined covers a land area of approximately $62,000 \mathrm{~km}^{2}$. It lies to the north-west of Nigeria and shares its borders with Niger Republic to the north, Katsina State to the East, Niger State to the South-east, Kwara State to the South and Benin Republic to the west. The southern boundary is arbitrarily defined by the Sudan savanna.

Like the rest of West Africa, the climate of the region is controlled largely by the two dominant air masses affecting the sub- region. These are the dry, dusty, tropical- continental (cT) air mass (which originates from the Sahara desert), and the warm, tropical- maritime (mT) air mass (which originates from the Atlantic Ocean). The influence of both air masses on the region is determined largely by the movement of the Inter-Tropical Convergence Zone (ITCZ), a zone representing the surface demarcation between the two air masses. The interplay of these two air masses gives rise to two distinct seasons within the sub-region. The wet season is associated with the tropical maritime air mass, while the dry season is a product of the tropical continental air mass. The influence and intensity of the wet season decreases from the West African coast northwards. Therefore, precipitation in the whole sub-region of West Africa depends on thunderstorm activity which occurs along disturbance lines called "line squalls" and, about 80 percent of the total annual rainfall for most places is associated with line squall activities which are prevalent between June and September (Adefolalu, 1986). 
Sokoto region experiences a short rainy period and a long dry season. The rainy season starts about mid-May in the southern fringes of the study area and about mid-June in the northern districts. The season ends about middle to late September in the northern districts, and early October in the southern districts. The dry season, on average, lasts between seven and eight months, usually from October to May. During the dry season the climate is dominated by the dry-dusty wind (harmattan), which blows Sahara dust over the land. When the dust hangs in the air, it causes serious air pollution which results in dirt virtually everywhere, and also reduces visibility.

With an annual average temperature of $38.3{ }^{\circ} \mathrm{C}$, Sokoto is one of the hottest cities in Nigeria, with maximum daytime temperatures hovering between 35 and $40^{\circ} \mathrm{C}$ which makes this dry environment quite unbearable. The warmest months are February, March and April when daytime temperatures can exceed $45^{\circ} \mathrm{C}$.

\section{Method of study}

To gain an insight into the nature of climatic variability within the climate system, it is necessary to study its components in a systematic way. For instance, records of rainfall, temperature, humidity, winds, clouds, pressure or sunshine will typically consist of a complex mixture of variations. Such variations can be separated or filtered out and identified as long-term trends, annual and semi-annual cycles, quasi-cyclical discontinuities, inter- and intra-annual variabilities. Previous studies have shown that among all the climatic elements, rainfall is the most variable element in northern Nigeria, both temporally and spatially and such variations can have significant impacts on economic activity (Kowal and Kanabe, 1972; Kowal and Kassam, 1978; Ekpoh, 1991, Adefolalu, 1986, Mortimore and Adams, 2001). Thus, in this study, emphasis is placed on precipitation, which is analyzed in terms of changes in the statistical distribution of the local rainfall. The mean, which represents the overall expectation of precipitation "normal" rainfall, is denoted by the symbol x. In precipitation analysis, the mean can only provide a preliminary guide to the characteristic of a location's overall precipitation regime. Summer (1988) notes that the mean is the measure generally used to represent the "normal" rainfall condition of a place. Consequently, annual totals are often converted into running means; the advantage of running means is in their ability to smooth the most extreme irregularities, making it easier to detect underlying patterns. The standard deviation $(\delta)$ describes the dispersion of rainfall from the mean value. The most frequently used measure of relative dispersion is the coefficient of variation $(\mathrm{CV})$. This is calculated by dividing the standard deviation by the mean and multiplying the result by 100 and is given as:

$$
\mathrm{CV}=\frac{\delta}{\overline{\mathrm{x}}} * 100
$$

Where:

$\mathrm{CV}=$ coefficient of variation; $\delta=$ standard deviation; $\overline{\mathrm{x}}=$ mean

For example, stations in areas of dry conditions typically produce coefficients in excess of 25 per cent.

To demonstrate the methodology used in this study to examine the degree of climatic variability, a hypothetical situation could be conceived. Under this scenario, it is assumed that annual rainfall has a Gausian (normal) distribution about the mean $(\underline{\mathrm{X}})$ and variance $(\delta)$ (Fig. 2a). In this model, long-term rainfall variations arise because of changes in either $\mathrm{X}$ or $\delta$ or both. In the first type of climate change, the mean rainfall changes, but the standard deviation remains the same (Fig. $2 b)$. Under this condition, the tolerable range of rainfall $(x+k)$ may not change immediately since this is a mild form of climate change. However, the frequency of negative extremes (-k) could be increased and the positive extremes $(+\mathrm{k})$ reduced. The second type of climate change considers a change in the standard deviation, with no change in mean rainfall (Fig. 2c). If the change results in the standard deviation becoming larger, then there would be increased risk from both deficient as well as excessive rainfall. In the third type of climate change both the mean and the standard deviation changes (Fig. 2d). This is a more severe type of climate change which can cause serious disruption of economic activities (Fukui, 1979; Parry, 1985a).

Following from the climate change model outlined above and in order to examine the type of climatic variation that have occurred within the period under consideration, rainfall data for 93 years was divided into three periods, viz: the long-term (1915-2008), the mid-term (1915-1967) and the short-term (1968-2008), and analyzed using the mean, the standard deviation, and the coefficient of variability. The results are presented in Table 1. 


\section{Results and discussion}

\subsection{Rainfall patterns and variability}

Table 1 shows the mean, the standard deviation and the co-efficient of variability for the long-term (1915-1968), the mid-term (1915-1967), and the short-term (1968-2008) rainfall regimes. From Table 1, the mean annual rainfall for the period 1915 to 2008 (long-term) was $678.90 \mathrm{~mm}$, with a standard deviation of 147.64 and coefficient of variation of 21.75 per cent. The mean annual rainfall for the period 1915 to 1967 (medium-term) was $724.97 \mathrm{~mm}$, with a standard deviation of 141.07 , and co-efficient of variability of 19.46 per cent. In the same vein, the mean annual rainfall for the period 1968 to 2008 (short-term) was $619.30 \mathrm{~mm}$, with a standard deviation of 135.48 , and a coefficient of variability of 21.88 per cent. A comparison of the short-term annual rainfall characteristic with the long-term data shows a drop of about 8.79 per cent $(59.6 \mathrm{~mm})$ in the mean rainfall, and 8.22 per cent in the standard deviation. In climatological sense, any climatic variation that involves a shift in both the mean and standard deviation is a serious climatic condition (Fukui, 1979).

A careful scrutiny of Figures 3 and 4 reveals two distinct climatic eras which are presented in Table 1 as mid-term and short-term. A comparison of these two periods shows that the mean annual rainfall for the period 1968-2008 was 14.58 per cent $(105.67 \mathrm{~mm})$ less than the mean rainfall for the period 1915-1967. The standard deviation also declined from 141.07 in the $1915-1967$ period to 135.48 in the 1968-2008 period. Additionally, the coefficient of variability increased slightly from 19.46 per cent in the $1915-1967$ period to 21.88 per cent during the 1968-2008 period.

From the foregoing, the results indicate that, among the three periods, the 1968-2008 showed the greatest tendency towards a dry trend, with a mean rainfall of only $619.30 \mathrm{~mm}$. Although the standard deviation was slightly lower than the other two eras, the co-efficient of variability was highest during this period. All these point to the fact that the climate of the region has undergone serious alterations in its underlying characteristics to the extent that a new mean and a new standard deviation were established. This confirms the onset of climate change in the region during the period 1968 to 2008. However, as cautioned by eminent scientists (Winstanley, 2003; Giannnini, Saravanan and Change, 2003), we should be slightly careful in rushing to conclusion as the observed pattern may just be a swing in the 200 year cycle of the region. Moreover, current flood episodes in the region seem to suggest a return of even wetter conditions. Thus the 'drama' that has been unfolding in the region since the last 40 years is that of a highly unpredictable climate, a juxtaposition of unexpected, extreme dry and wet years.

\subsection{Inter-annual rainfall variability}

Inter-annual rainfall variation is the broadest time scale over which precipitation varies. Sumner (1988) has observed that this scale is important since any long-term trends, be they a consistent decrease or increase, or a notable regular fluctuation may have a potentially catastrophic effect on the well-being of an area and its people. Such trends will have an impact over time spans of the order of decades; as was the case with the persistent droughts of the 1970s, 1980s and 1990s (Bunting et al., 1976; Nicholson, 1985; Ingram, Roncoli and Kirshen, 2002). The yearly fluctuation in total rainfall for Sokoto is shown in Figure 3. A close scrutiny of Figure 3 shows that two climatic eras are discernible. The first era started from 1915 and lasted till about 1967 when the mean rainfall stabilized at about $680 \mathrm{~mm}$. The second climatic era started in 1968 and continued up to 2008 when the mean rainfall declined to about $600 \mathrm{~mm}$. The situation of declining rainfall during the 1968 to 2008 era is further amplified by the illustration in Figure 4 which shows a five-year running mean for the long term rainfall from 1915 to 2008. From the two figures (Figures 3 and 4), it is evident that rainfall in the Sokoto region during the 1968-2008 has declined substantially to the extent of establishing a new mean that is 8.8 percent lower than the long-term mean.

\subsection{Intra-annual rainfall variability}

It is an undeniable fact the northern Nigeria receives the least amount of rainfall in Nigeria because of its hinterland location. Figure 5 shows the mean monthly rainfall distribution for Sokoto for the period 1915 to 2008 . From Figure 5, rainfall in Sokoto should normally start from April and end by October. July is the month with the maximum rainfall and the rainfall pattern is that of a single maximum. In water resources planning and management, Sokoto State has an effective five months, from May to September, for the recharge of surface and sub-surface reservoirs. Figures $6-8$ show the pattern of rainfall during drought years in comparison with the mean monthly rainfall distribution for Sokoto. A closed scrutiny of the three diagrams shows that the pattern for 1973 and 1993 are very similar while that of 1984 is different. From Figures 6 and 8, besides the total annual rainfall being far less than the long-term mean, it is evident that the 1973 and 1993 rainfalls in Sokoto started late but ended early, thus reducing the length of the growing season for the drought years. It is also evident that there 
was a false onset of the rains in March of those years. The 1984 drought year (Figure 7) shows a delayed onset and early cessation of the rains in that year which led to drastic reduction of the length of the rainy season.

As observed earlier, the mean annual rainfall since the late 1960s up to 2008 has decreased over 8 per cent, in comparison with the 1915 to 2008 long-term mean rainfall. The drought years, 1972/73, 1983/84 and 1992/93 did not only experience below average annual rainfall (for instance, the 1984 annual rainfall was 58.8 percent less than the long-term mean), but also experienced late onset and early cessation, which led to a drastic reduction in the length of the rainy season. In addition to these distortions in the rainfall characteristics of the region, the 1972/73 and 1992/93 rainfall seasons also experienced false onsets.

Anthropogenic climatic change may well increase the likelihood of such events occurring in the future and it is reasonable to assume that the probability of abrupt climatic shifts may increase with increasing rates and magnitudes of greenhouse gas emissions and consequent increases in global mean surface temperature. The consequences of such events for the Sahel would be dramatic. Climatic models indicate that the result would probably be a rapid onset of aridity lasting decades to centuries.

\section{Conclusion}

Analysis of the climate of north-western Nigeria for the period 1915-2008 confirms that the rainfall of that region has fluctuated substantially. Such fluctuations affect both inter-annual and intra-annual rainfall patterns. Fluctuations in inter-annual rainfall totals are not confined to the mean-state conditions but also affect the standard deviation and the coefficient of variation. With regard to intra-annual rainfall, the study has shown that rainfall between 1967 and 2007 has fluctuated enormously not only in terms of total receipts, but also in the dates of rainfall onset and cessation, as well as in the length of the rainy season. Furthermore, there is evidence of incessant "false onset" in recent rainfall characteristic.

In general, the Sahel is a climatically sensitive region in which rainfall exhibits considerable variability on multiple timescales. Being the transition zone between humid tropical Africa and arid Sahara, the Sahel is particularly sensitive to changes in the African monsoon, which are modulated by changes in solar radiation and sea-surface temperatures in the southern Pacific called El Nino. While the Sahel has experienced numerous dry episodes in the past, variations in the climate since the late 1960s tend to suggest a desiccation of unprecedented proportion within the context of climate variability over the historical period in north-western Nigeria. Although the changing rainfall regime has been sustained for a period of over 30 years, it is not possible to confirm if the shift is not just another cycle in the long history of the region.

To check the diminishing rainfall regime of the area, the study suggests that local and regional development policies that recognize the fragile nature of semi-arid environments should be adopted in pursuing livelihoods especially in the area of agriculture. More effort should be made to discourage deforestation while encouraging soil and water conservation strategies. At the same time, governments at both the local, state and national levels should embark upon massive tree planting projects throughout the northern parts of Nigeria. Also, water could be transferred from rivers with surplus yield in southern Nigeria to regions of water deficit in northern Nigeria. Such transfers should be done through pipelines to avoid excessive loss through evaporation and seepage which are associated with canalization. These suggestions, if implemented, will impact positively on the regional weather and climate, improve the hydrological regime and stabilize the ecosystem. Hopefully, the desiccation of the last 40 years would be reversed, with droughts becoming less frequent.

\section{References}

Adefolalu, D. O. (1985). Further aspects of the Sahelian drought as evident from rainfall regime in Nigeria. Archive of Meteorology, Geophysics and Bioclimatology, 36, 277-295. doi:10.1007/BF02263134, http://dx.doi.org/10.1007/BF02263134

Adefolalu, D. O. (1986). Rainfall trends in Nigeria. Theoretical and Applied Climatology, 37, 205-219.doi:10.1007/BF00867578, http://dx.doi.org/10.1007/BF00867578

Akonga, A. Z. (2001) The causes and impacts of drought. ANIS Monograph, 3, 1-6.

Biasutti, M. \& Giannini, A. (2006). A robust Sahel drying in response to late 20th century forcing. Geophys. Res. Letters, 11, L 11706.

Bunting, A. H., Dennet, M. D., Elston, J. \& Milford, J. R. (1976). Rainfall trends in the West African Sahel. Quarterly Journal Royal Meteorological Society, 102, 59. doi:10.1002/qj.49710243105, http://dx.doi.org/10.1002/qj.49710243105 
Camberlin, P. \& Diop, M. (2003). Application of daily rainfall principal component analysis to the assessment of the rainy season Characteristics in Senagal. Climate Research, 23, 159-169. doi:10. 3354/cr023159, http://dx.doi.org/10.3354/cr023159

Charney, J., Quirk, W. J., Chow, S. H. \& Kornfield, J. (1977). A comparative Study of the effects of albedo change on drought in semi-arid regions. Journal of the Atmospheric Sciences, 34(a), 1366.

Dai, A., Lamb, P., Trenberth, K. E., Hulme, M., Jones, P. D. \& Xie, P. (2004). The recent Sahel drought is real. Int. J. Climatology, 24, 1323-1331. doi:10.1002/joc.1083, http://dx.doi.org/10.1002/joc.1083

Diop, M. (1996). A propos de la duree de la Saison des pluies au Senegal. Secheresse, 7, 7-15.

Ekpoh, I. J. (1991). The Effects of Climatic Variability on Agriculture in Northern Nigeria. PhD Dissertation, University of Birmingham, Birmingham B 15 2TT, United Kingdom.

Ekpoh, I. J. (1999a). Rainfall and Peasant Agriculture in Northern Nigeria. Global Journal of Pure and Applied Sciences, 5(1), 123-128.

Ekpoh, I. J. (2007). Climate and Society in Northern Nigeria: Rainfall variability and farming. The International Journal Series on Tropical issues, 8(3), 157-162.

Federal Republic of Nigeria (1999). Combating Desertification and Mitigating the Effects of Drought in Nigeria. National Report. Recife, Brazil.

Floyd, B. N. \& Ekpoh, I. J. (2007). Transforming traditional agriculture. Global Journal of Social Sciences, 6(2), 97-102.

Foley, J. A. \& Coe, M.T. (2001). Shrinking African Lake offers Lesson on Finite Resources. Journal of Geophysical Research, 8, 122-127.

Foley, J. A., Coe, M. T., Schaeffer, M. \& Wang, G. (2003). Regime shifts in the Sahara and Sahel: interactions between ecological and climatic systems in Northern Africa. Ecosystems, 6(6), 524-532. doi:10.1007/s10021-002-0227-0, http://dx.doi.org/10.1007/s10021-002-0227-0

Folland, C. K., Palmer, T. N. \& Parker, D. E. (1986). Sahel rainfall variability and worldwide sea temperatures, 1901-85. Nature, 320, 602-606. doi:10.1038/320602a0, http://dx.doi.org/10.1038/320602a0

Fukui, H. (1979). Climatic Variability and Agriculture in tropical moist regions. In World Meteorological Organisation, Proceedings of the World Climate Conference, WMO-No.537, WMO, Geneva.

Giannini, A., Saravanan, R. \& Change, P. (2003). Ocean forcing of Sahel Rainfall on inter-annual to inter-decadal timescales. Science, 302, 1027-1030. doi:10.1126/science.1089357, http://dx.doi.org/10.1126/science.1089357

Gonzalez, P. (2001). Desertification and shift of forest species in the West African Sahel. Climate Res, 17, 217-228. doi:10. 3354/cr017217, http://dx.doi.org/10.3354/cr017217

Houndenou, C. \& Hernandez, K. (1998). Climate of the Sahel 1961-1990. Benin, Secheresse, 9, 23-34.

Hulme, M. (2001). Climate perspectives on Sahelian desiccation; 1973-1998. Global Environmental Change, 11, 19-29. doi:10.1016/S0959-3780(00)00042-X, http://dx.doi.org/10.1016/S0959-3780(00)00042-X

Hulme, M., Doherty, R., Ngara, T., New, M. \& Lister, D. (2001). African Climate Change: 1900-2100. Climate Research, 17, 145-168. doi:10 3354/cr017145, http://dx.doi.org/10.3354/cr017145

Ingram, K. T., Rancoli, M. C. \& Kirshen, P. H. (2002). Opportunities and constraints for farmers of West Africa to use seasonal precipitation forecasts with Burkina Faso as a case study. Agricultural systems, 74, 331-349. doi:10.1016/S0308-521X(02)00044-6, http://dx.doi.org/10.1016/S0308-521X(02)00044-6

IPCC. (2001). Climate Change: Impacts, Vulnerability and Adaptation. Working group II, WMO, Geneva

IPCC. (2007). Climate Change 2007: Impacts, adaptation and vulnerability. WMO, Geneva.

IPCC. (2007). Climate Change 2007: The physical science basis. Summary for Policy Makers.

IPPC. (2007). Climate Change 2007: Fourth Assessment Report (AR4).

Kalu, A. E. (1987). The recurrence of severe droughts in northern Nigeria. Proceedings of the 1985 Commonwealth Meteorologists Conference. Meteorological Office College, Reading.

Kamara, S. I. (1986). The origin and types of rainfall in West Africa. Weather, 41, 48-56. 
Kowal, J. M. \& Kanabe, D. T. (1972) An Agro-climatic Atlas of the Northern States of Nigeria. Ahmadu Bello University Press, ABU, Zaria.

Kowal, J. M. \& Kassam, A. H. (1978) Agricultural Ecology of the Savanna: A Study of West Africa. Clarendon Press, Oxford.

Le Barbe, L.,\& Lebel, T. (1997). Rainfall Climatology of the HAPEX-Sahel region during the years 1950-1990. Journal of Hydrology, 188-189, 43-73. doi:10.1016/S0022-1694(96)03154-X, http://dx.doi.org/10.1016/S0022-1694(96)03154-X

Lockwood, J. G. (1988). Climate and Climatic Variability in semi-arid regions at low latitudes. M. L.Parry, T.R.Carter and N.T.Konijn (eds), The impact of climate variations on Agriculture: Assessments in semi-arid region. Kluner Academic Publishers, Dordrecht.

Mortimore, M., \& Adams, W. M. (2001) Farmer adaptation, change and crisis in the Sahel. Global Environmental Change, 11, 49-57. doi:10.1016/S0959-3780(00)00044-3, http://dx.doi.org/10.1016/S0959-3780(00)00044-3

Nicholson, S. E. (1985). Sub- Saharan rainfall, 1976-1984. Journal of Applied Meteorology, 24, 1388-1391. doi:10.1175/1520-0450(1985)024<1388:SSR >2.0.CO;2, http://dx.doi.org/10.1175/1520-0450(1985)024<1388:SSR >2.0.CO;2

Nicholson, S. E. (1993). 'An Overview of African rainfall fluctuations of the last decade'. Monthly Weather Review, 111, 1646-1654. doi:10.1175/1520-0493(1983)111<1646:SSRITY>2.0.CO;2, http://dx.doi.org/10.1175/1520-0493(1983)111<1646:SSRITY>2.0.CO;2

Nicholson, S. E., \& Tucker, C. J. (1998). Desertification, drought, and surface vegetation: an example from the West African Sahel. Bulletin of the American Meteorological Society, 79(5), 815-829. doi:10.1175/1520-0477(1998)079<0815:DDASVA>2.0.CO;2, http://dx.doi.org/10.1175/1520-0477(1998)079<0815:DDASVA>2.0.CO;2

Olaniran, O. J. \& Summer, G. N. (1989). "A study of climate variability in Nigeria based on the onset, retreated and length of the rainy season." Int. Journal of Climatology, 9, 253-269. doi:10.1002/joc.3370090304, http://dx.doi.org/10.1002/joc.3370090304

Olaniran, O. J. (1991). Evidence of climatic change in Nigeria based on annual rainfall series 1919-1985. Climate Change, 19, 507-520. doi:10.1007/BF00140169, http://dx.doi.org/10.1007/BF00140169

Parry, M. L. (1985a). Estimating the sensitivity of natural ecosystems and agriculture to climate change. Guest editorial. Climate Change, 7, 1-3. doi:10.1007/BF00139437, http://dx.doi.org/10.1007/BF00139437

Quinland, F. T. (1986). Comments on Sahel: The changing rainfall regime and the "normals" used for its assessment. J. Climatology, 2, 257.

Sumner, S. (1988) Precipitation: Process and Analysis. John Wiley \& Sons, Chichester.

Tarhule, A. \& Woo, M. (1998). Changes in rainfall characteristics of northern Nigeria. International Journal of Climatology, 18, 1261-1271. doi:10.1002/(SICI)1097-0088(199809)18:11<1261::AID-JOC302>3.0.CO;2-Z, http://dx.doi.org/10.1002/(SICI)1097-0088(199809)18:11<1261::AID-JOC302>3.0.CO;2-Z

Todorov, A. V. (1985). Sahel: the changing rainfall regime and the "normals" used for its assessment. Journal of Climate and Applied Meteorology, 24, 97-107. doi:10.1175/1520-0450(1985)024<0097:STCRRA>2.0.CO;2, http://dx.doi.org/10.1175/1520-0450(1985)024<0097:STCRRA>2.0.CO;2

Traore, S. B., Reyniers, E. N., Vaksmann,M., Kouressy, M., Yattara, K., Yorote, A., Sidibe, A., \& Kone, B. (2000). Adaptation a la secheresse des ecotypes locaux de sorgbo du Mali. Secheresse, 11, 227-237.

Tucker, C. J., Dregne, H. E., \& Newcomb, W. W. (1991). Expansion and contraction of the Sahara desert from 1980 to 1991. Science, 299-301.

Winstanley, D. (1985). Africa in drought: a change of climate? Weatherwise, 38 (2), 75-79. doi:10.1080/00431672.1985.9933288, http://dx.doi.org/10.1080/00431672.1985.9933288 
Table 1. Temporal rainfall variations at Sokoto for different climatic eras

\begin{tabular}{|l|l|l|l|}
\hline PERIOD & MEAN & STD. DEV. & C.V (\%) \\
\hline $\begin{array}{l}\text { (a) } \\
\underline{\text { Long-term }} \\
1915-2008\end{array}$ & 678.90 & 147.64 & 21.75 \\
\hline $\begin{array}{l}\text { (b) } \\
\text { Medium-Term }\end{array}$ & 724.97 & 141.07 & 19.46 \\
\hline $\begin{array}{l}\text { (c) } \\
\text { Short-Term }\end{array}$ & 61967 & 135.48 & 21.88 \\
\hline $1968-2008$ & 6190 & & \\
\hline
\end{tabular}

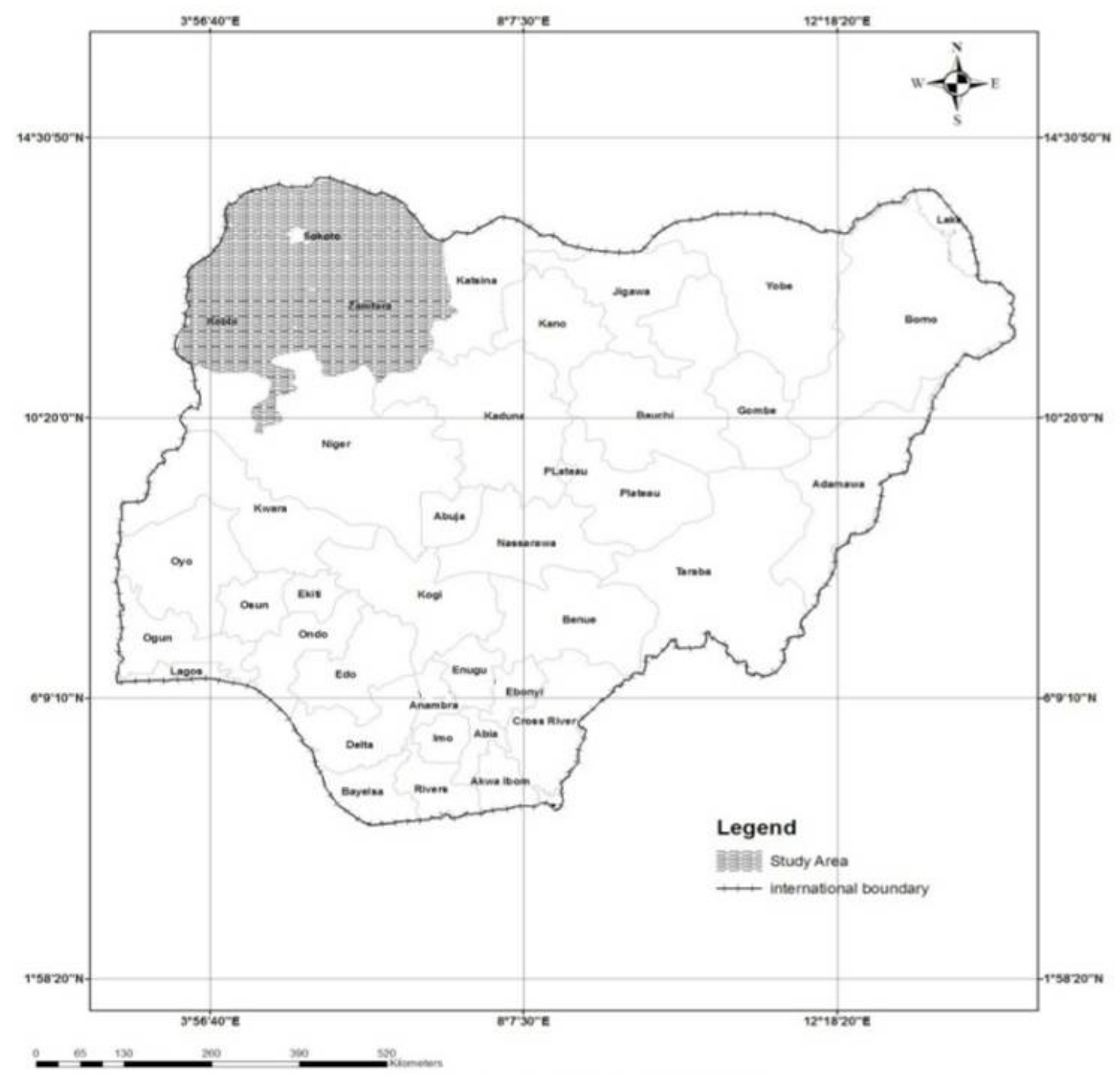

Figure 1. Map of Nigeria showing the study area 


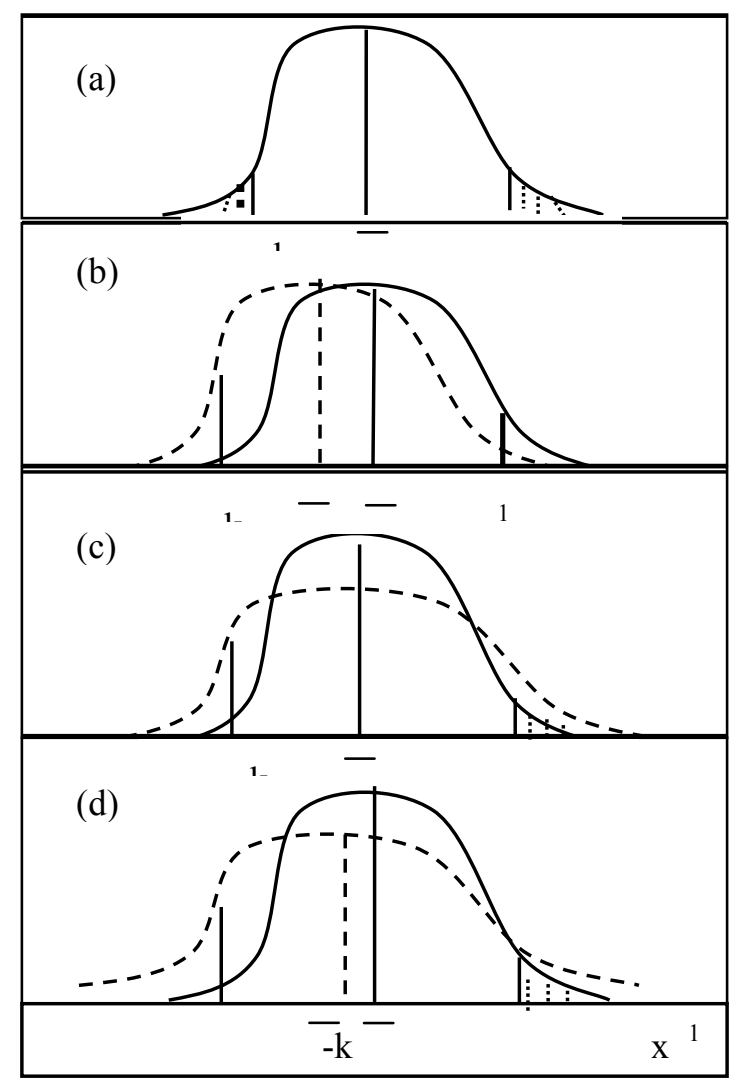

Figure 2. (a-d) Types of climatic change (using rainfall variations)

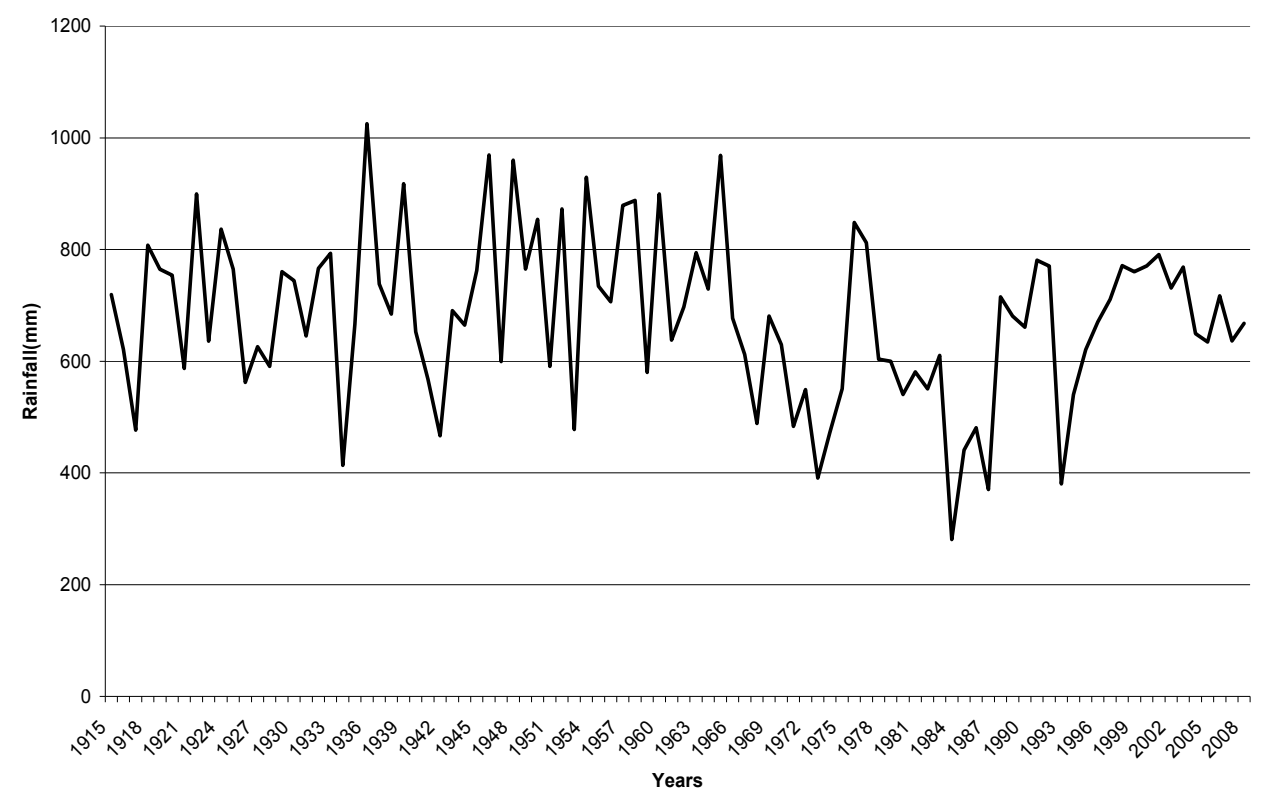

Figure 3. Time series of annual rainfall for Sokoto: 1915-2008 


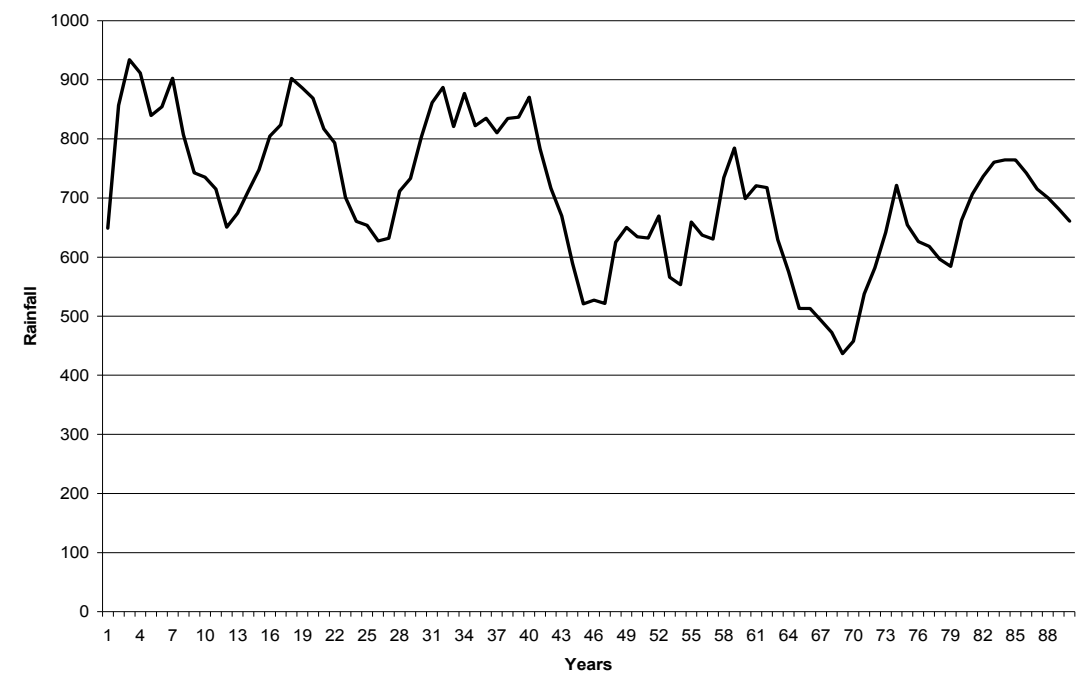

Figure 4. Sokoto Rainfall: 5-Year running means

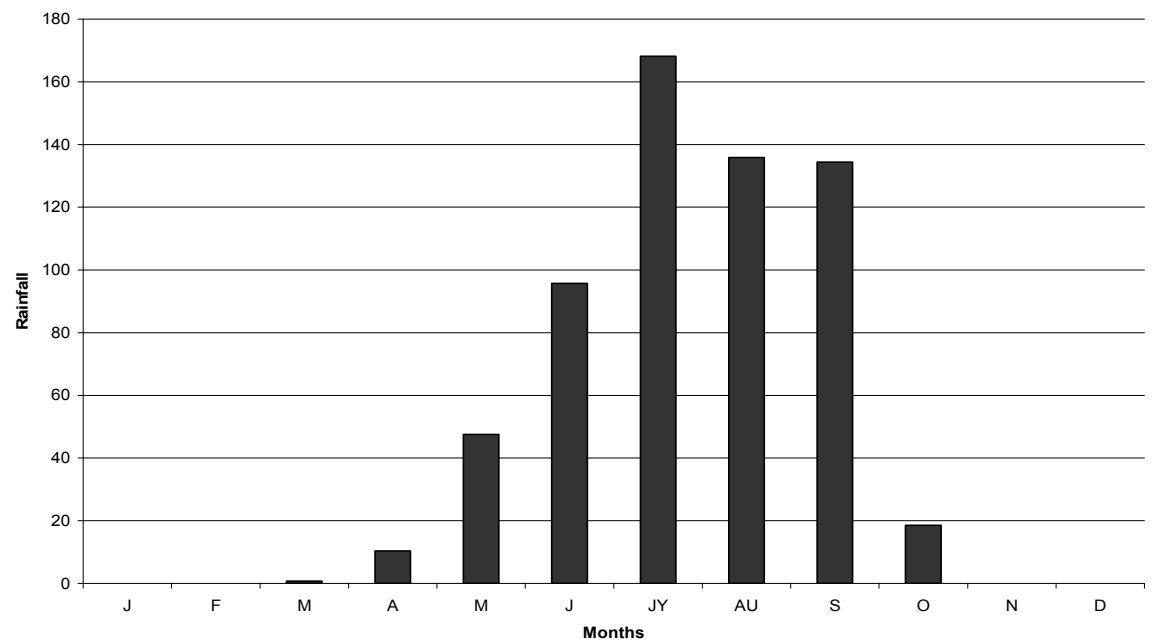

Figure 5. Mean monthly rainfall distribution for sokoto

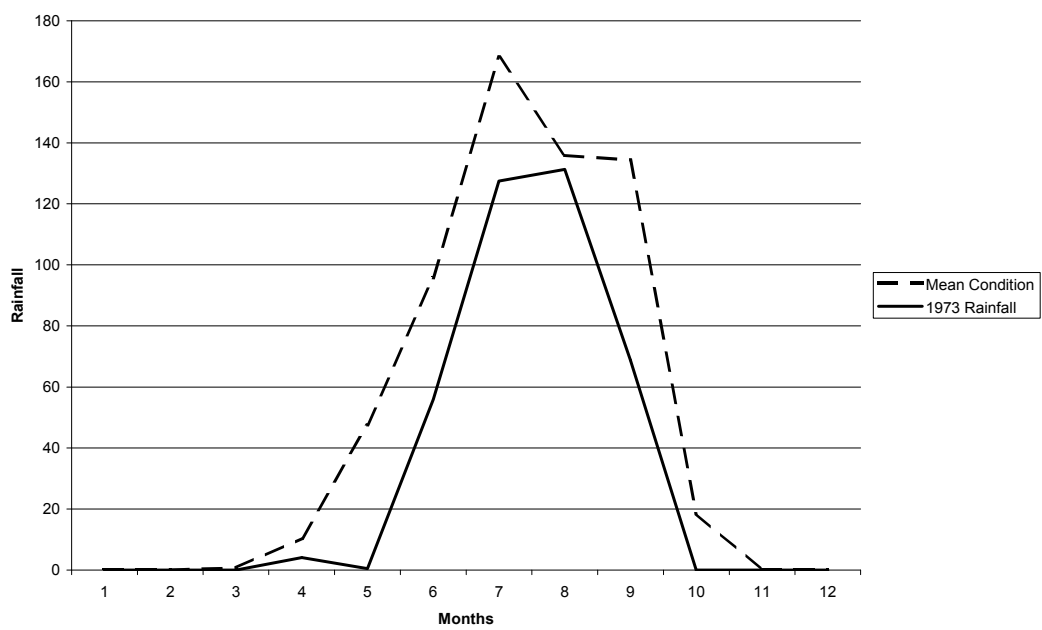

Figure 6. Comparison of 1973 rainfall (drought year) with mean condition 


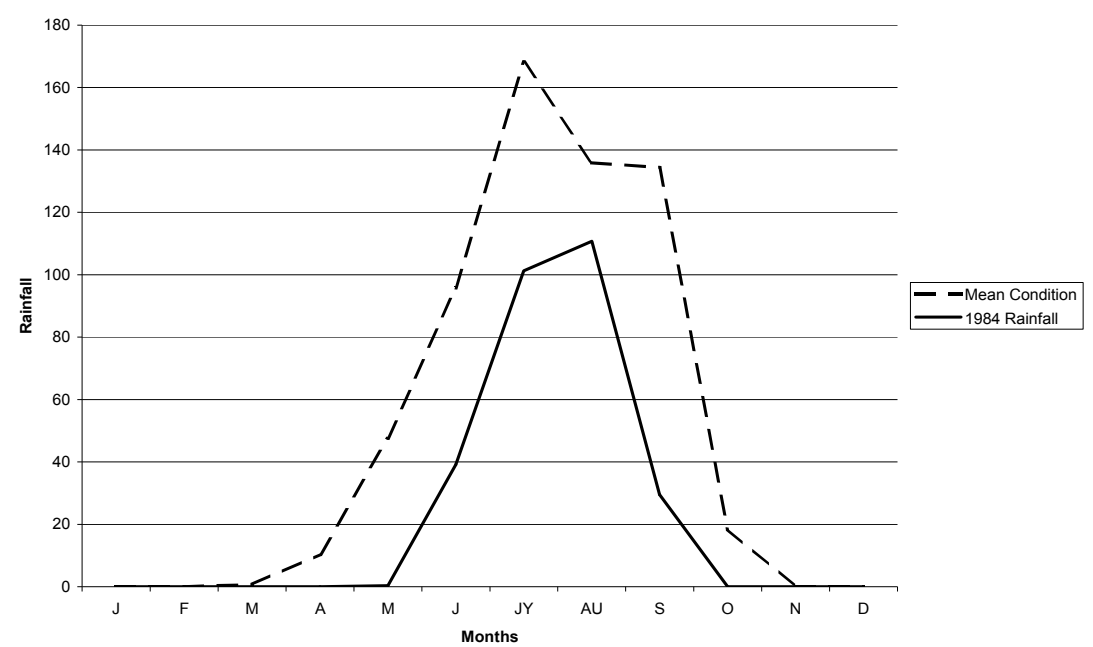

Figure 7. Comparison of 1984 rainfall (drought year) with mean condition

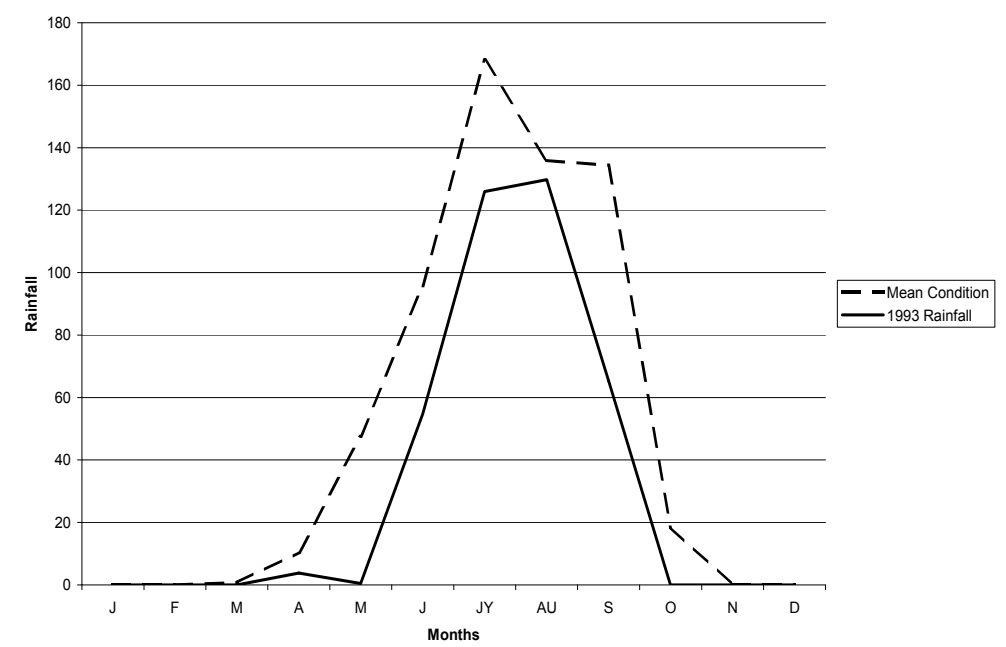

Figure 8. Comparison of 1993 rainfall (drought year) with mean condition 